\title{
'Rabone' and four unresolved problems in mental health law
}

\author{
George Szmukler, ${ }^{1}$ Genevra Richardson, ${ }^{2}$ Gareth Owen ${ }^{1,3}$
}

The Psychiatrist (2013), 37, 297-301, doi: 10.1192/pb.bp.113.043273

${ }^{1}$ Institute of Psychiatry, King's College London; ${ }^{2}$ King's College London;

${ }^{3}$ South London and Maudsley NHS Foundation Trust

Correspondence to George Szmukler (george.szmukler@kcl.ac.uk)

First received 4 Mar 2013, final revision 8 May 2013, accepted 22 May 2013
Summary In a landmark decision, the Supreme Court of the UK ruled that the state has a special operational duty to protect the right to life in informal psychiatric in-patients ('Rabone case'), in sharp distinction to general medical or surgical patients. We will argue that the significance of this case is general, not just local, and that it exposes four important unresolved problems in mental health law: the place of decision-making capacity; the meaning of 'informal' admission; parity between mental and physical health; and the accuracy of risk assessment.

Declaration of interest None.

Article 2 of the European Convention on Human Rights (ECHR) states that 'Everyone's right to life shall be protected by law'. This has been interpreted by the European Court of Human Rights as imposing three distinct duties on the state: (a) a duty to refrain from taking life (save in exceptional circumstances); (b) a duty to conduct a proper and open investigation into deaths for which the state might be responsible; and (c) a positive duty to protect life in certain circumstances. The last point, in turn, has two elements: the first is a general duty to put in place a legal and administrative framework designed to deter threats to life; the second, called the 'operational duty', is an obligation on the state to take reasonable measures when there is a 'real and immediate risk to life' to an identified person to avoid that risk materialising. The risk is one the authority knows about or should have known about. The obligation should not impose an impossible or disproportionate burden on the relevant authorities. ${ }^{1}$

The legislators drafting Article 2 after the Second World War had lived through the horrors of early 20thcentury Europe, with its death squads and extrajudicial state killings. These possibilities were in the minds of the legislators. Those that may arise in healthcare settings with regard to the right to life - settings where saving life and furthering the quality of life in the context of disease is the purpose - were much less in the minds of the European Court of Human Rights legislators. Interpreting Article 2 in healthcare settings is a relatively recent area of legal activity. Cases considered by the European Court of Human Rights have established that where a person is detained by the state as a prisoner, an operational duty under Article 2 to prevent a suicide applied if certain conditions were met. ${ }^{2,3}$ It has also been extended to other detainees and to army conscripts. A later judgment by the House of Lords (precursor to the UK Supreme Court) ruled that it applied similarly to a detained patient in a psychiatric hospital. ${ }^{4}$ The categories of persons were all ones where they fell significantly under the control of the state, and in most cases found themselves in such circumstances against their will.

In a landmark decision, the new Supreme Court of the UK ruled that this operational duty imposed by Article 2 applied to voluntary as well as detained psychiatric in-patients. ${ }^{5}$ This article examines some significant implications of this decision for mental health law and for understandings of the nature of mental healthcare.

\section{The case}

The history is taken from the High Court and Court of Appeal judgment before reaching the Supreme Court. ${ }^{6,7}$ Twenty-four-year-old Melanie Rabone died by hanging on 20 April 2005. The previous day she had been allowed home leave from a psychiatric unit where she had been admitted on 11 April. She had had depression since 2000. On 4 March 2005 she had been admitted to hospital after a suicide attempt where she tied a pillowcase around her neck. She was discharged on 18 March after an earlier overnight leave on the 14th. She then went on a family holiday to Egypt, but on 31 March, after her return, she cut her wrists with broken glass. She was not readmitted, apparently as no bed was available. Follow-up with the trainee psychiatrist on 6 April revealed that she had occasional thoughts of suicide and frequent thoughts of self-harm. On 11 April she tied lamp flex around her neck. Her face became swollen and there were ligature marks around her neck. Her parents also found a hosepipe and tape hidden in her room. The medical notes stated she had a 'severe depressive episode . . .? Psychosis, High risk [of self-harm] and suicide'. She was admitted informally, prescribed medication and placed under 15-minute observations. A risk assessment using trust documents was commenced by one of the nurses on the ward, but further information was required for it to be completed. On 13 April, Melanie's father 'expressed grave 
concern about Melanie's current condition and her being sent out on leave or discharged too soon'. There were further conversations involving her parents along these lines during the week. Nursing reports in the notes from 16 April stated that her mood was lifting, but Mr Rabone telephoned the ward on 18 April saying that she was not improving and that she had expressed fleeting suicidal thoughts. On 19 April, her consultant, who had been on leave when Melanie was admitted, returned from leave. The following was the record in the nursing notes of a meeting with Melanie and her mother: ${ }^{7}$

'Dr Meagher, Dr Davies, SN Erin Booth. Melanie seen with her mother. She states she self harmed at home due to feeling angry at herself because of the thoughts she has. Realises that does not achieve anything. Feels trapped at home "slightly". Would like to be more independent. Stated enjoyed recent trip to Egypt. Does not regret leaving employment. Wishes to look for something else. Does not want to stay in destructive cycle. Struggling to recognise how she can stop same. Feels she is lacking in confidence and has low self-esteem. Identified ways of addressing issues herself. Would like to leave for up to a week. Would start looking for job and see friends. Leave agreed as long as Melanie when seeing her friends does not talk about herself and become centre of attention. Reasons for this also discussed. Mother concerned about same as unable to keep eye on her. Dr Meagher advised Melanie has to take responsibility for own actions and when has previously harmed herself it has been when parents keeping an eye on her. Melanie in agreement that will not self-harm.

Plan - for 2 days/nights leave.'

Melanie left the ward with her mother that evening, and sometime after $5 \mathrm{pm}$ the next day she hung herself from a tree in a park. The hospital conceded the decision to allow home leave was negligent.

Both the High Court and the Court of Appeal judged that an operational duty under Article 2 did not apply. Further appeal was allowed to the Supreme Court, which ruled that there was an operational duty falling on the mental health trust under Article 2 to protect the life of Melanie and that the trust failed to take reasonable measures to do so.

\section{Exploring reasons for the Supreme Court's decision}

Differences between the detained patient, the informal psychiatric patient, and the general medical or surgical patient

The Supreme Court ruling ${ }^{5}$ saw the Rabone case, now involving an informal psychiatric patient, as an extension of the involuntary psychiatric case where an operational duty under Article 2 was held to obtain; ${ }^{4}$ the responsible authority had (or should have had) the requisite knowledge of a 'real and immediate' risk to the person's life from selfharm and that there were reasonable measures that could have been taken to avoid or prevent that risk.

What was the reasoning? Much turned on the degree of control exercised by the state on the life at risk. The court held that the position of the informal psychiatric patient was relevantly different to that of the general medical or surgical patient, but to a large degree similar to that of the detained psychiatric patient.
The court held that whereas autonomous individuals have the right to act as they wish, for those who are 'vulnerable', there may be a special duty to protect them.

'As regards the voluntary psychiatric patient who is at risk of suicide and the patient suffering from a life-threatening physical illness who is in an "ordinary" hospital setting, the nature of the risk to which these two categories of patient are exposed is very different. In the case of the suicide of a psychiatric patient, the likelihood is that, given the patient's mental disorder, her capacity to make a rational decision to end her life will be to some degree impaired ... Melanie was admitted to hospital because she was suffering from a mental disorder and had attempted to commit suicide. The very reason why she was admitted was because there was a risk that she would commit suicide from which she needed to be protected. On the other hand, the patient who undergoes surgery will have accepted the risk of death on the basis of informed consent. She may choose to avoid the risk by deciding not to go ahead with the medical treatment'.5

The analogy with the patient detained under the Mental Health Act 1983 was regarded as much closer than the analogy with the patient admitted for treatment of a physical illness or injury. Lord Dyson observed:

'By reason of her mental state, [Melanie Rabone] was extremely vulnerable. The trust assumed responsibility for her. She was under its control. Although she was not a detained patient, it is clear that, if she had insisted on leaving the hospital, the authorities could and should have exercised their powers under the [Mental Health Act] to prevent her from doing so. In fact, however, the judge [in the High Court] found that, if the trust had refused to allow her to leave, she would not have insisted on leaving. This demonstrates the control that the trust was exercising over Melanie. In reality, the difference between her position and that of a hypothetical detained psychiatric patient, who (apart from the fact of being detained) was in circumstances similar to those of Melanie, would have been one of form, not substance,

\section{A 'real and immediate' risk and measures to prevent it}

Based on the expert evidence, the court judged there was a 'real and immediate' risk in this case. A key difference between the psychiatric and general patient was stated to be the power of detention available over the former when there was such a risk. There was also the implication that this was a measure that did not impose an unreasonable burden on the authority.

The expert risk assessment accepted by the court was that the risk of Melanie dying by suicide 'was approximately $5 \%$ on 19 April (after leaving hospital) increasing to $10 \%$ on 20 April and $20 \%$ on 21 April'. ${ }^{5}$ This expert had described the risk of suicide as 'low to moderate'. The other expert had put the risk at $70 \%{ }^{6}$

\section{Four problems raised by the judgment}

We will examine, first, some of the underlying assumptions made by the court concerning the position of the psychiatric patient in relation to other patients, and second, the basis for the assessment of risk.

Let us first set out the groups of persons who are compared in the Supreme Court judgment:

- prisoners

- detained psychiatric patients 
- informal psychiatric patients

- general medical and surgical patients.

There is a subgroup of general medical and surgical patients that is not mentioned at all by the court - patients who are unable to give consent because they lack the capacity to do so. This group may even constitute the majority of patients nowadays in, what the court refers to as, 'ordinary hospitals', largely because of aging-associated disorders such as delirium and dementia. ${ }^{8}$ Among this group of patients there will be a significant number who are legally restrained or restricted in their movements, or indeed effectively detained, under the Mental Capacity Act 2005. Restriction or the use of force under the Act is permitted when the intervention is necessary in the 'best interests' of the person - that is, to prevent harm and only when it is proportionate to the seriousness of the harm and its likelihood. It is an everyday event on medical and surgical wards that confused patients, for example, post-operatively, are restrained while attempting to remove necessary medical devices such as intravenous drips or nasogastric tubes, or while attempting to leave the ward. Unlike the Supreme Court, we will recognise this category.

\section{Problem 1: the place of decision-making capacity}

The Supreme Court judged that the state's operational duty to protect life was engaged for some groups, but not for others. The Rabone decision extends the operational duty to informal, non-detained psychiatric patients. Their vulnerability due to mental illness is as for detained patients. Although an admission may be informal, the Mental Health Act can be used to detain the patient. Thus there is a level of control exercised by the hospital authorities that is one short step from that exercised over the detained patient. Indeed, many patients agree to a voluntary admission because of an unspoken fear that refusal will result in an involuntary admission, or they may even be explicitly threatened with such an order. Therefore, in respect of the operational duty, the Supreme Court drew a line between informal psychiatric patients and general patients. For the latter, where the element of control was deemed to be less, state-mandated clinical governance and associated arrangements designed to protect patients - minimum professional standards for training and registration, mechanisms for monitoring practice, stipulated measures to be taken if performance is below standard, inspections, audit, and so on - were held to suffice.

However, by omitting any mention of general patients who lack capacity and whose movements may be legally restricted by hospital authorities under the Mental Capacity Act, the position of the line is obscured. These patients are unable to give informed consent to dangerous procedures. They are vulnerable as a result of their illness and the associated disturbance of mind. We do not see why, on the basis of the Supreme Court's reasoning, the operational duty should not apply to this category of patient as well.

This leads to a general problem. By placing substantial weight on the protection of general patients afforded through their ability to give informed consent, a question concerning the place that should be given to decisionmaking capacity is thus raised. How, it may be asked, does the position of the informal psychiatric patient with capacity differ from the general patient with capacity? Both groups of patient exist, ${ }^{9}$ but retention of capacity only offers legal protection against involuntary treatment for the general medical or surgical patient. Lady Hale's statement in the judgment that 'we must start from the proposition that [psychiatric patients] are entitled to the same freedom and autonomy as everyone else ${ }^{5}$ thus remains only an aspirational starting place, not a real one.

One of us has argued that the law's inability to start from this proposition using capacity-based mental health law for all patients, whether psychiatric or general, unfairly discriminates against psychiatric patients, whose 'autonomy' and rights to self-determination thus are not accorded the respect given to general patients. ${ }^{10}$ A non-discriminatory law would require a lack of decision-making capacity as the first step in the consideration for involuntary treatment for all patients. Perhaps Melanie lacked capacity, but we do not know, as it was not assessed (nor, of course, was this required under the Mental Health Act).

\section{Problem 2: the place of informality}

It might be argued that this ability to override treatment refusals by psychiatric patients who retain decision-making capacity gives rise to a further problem. The court saw little difference between the informal and the detained psychiatric patient, since the former could either be detained if treatment were refused or compliance with treatment could be induced by the patient's fear that they would be detained if they failed to agree. But this apprehension does not seem to exist in the same way among general patients. Why might that be? After all, law, such as the Mental Capacity Act, may authorise deprivations of liberty of the general patient and similar issues around professional concerns about a refusal of treatment and pressures to comply can arise. Why does the possibility of detention so often imply a fact of detention in psychiatry? The answer may be, in part at least, that unlike the position of the general patient, the retention of decision-making capacity by the informal psychiatric patient offers no legal protection against non-consensual treatment. An absence of capacity is not a necessary criterion for involuntary detention under the Mental Health Act and only in relation to electroconvulsive therapy is it required for involuntary treatment. A loss of decision-making capacity does not need to be demonstrated as it does for the general patient - a significant hurdle to the imposition of involuntary treatment is thus absent.

Regardless of the question of capacity, we believe that the lack of substance to informality in psychiatric treatment - a practice of valuing non-coercion in psychiatric care - is being accepted too easily in the Supreme Court judgment. There is a problem with how this acceptance may both exacerbate defensive psychiatric practice and make society disproportionately aware of the potential of the state to detain people with mental disorder. The presence of compulsory powers, so well known to many psychiatric patients, brings an inevitable shadow. The aim should be to reduce this shadow and return some reality to the notion of 
informality. The Supreme Court decision does not forward that aim.

\section{Problem 3: parity between mental and physical health}

Should a line be drawn at all within the larger category of 'patients' as to who does and who does not engage the operational duty? When we are admitted to hospital do we not expect that everything that can be reasonably done to ensure our safety will be done? Medicine does not use non-medical criteria to determine the quality of care offered. The same clinical governance principles and regulations apply equally across all health services, including mental health services. Social policy concerning healthcare does not demarcate categories of patient to whom a greater or lesser duty of care is owed. Why are clinical governance and the law of negligence not regarded as sufficient for both the general and the psychiatric patients, or, if they are not regarded as sufficient, then why should the operational duty under Article 2 not apply to all patients? The Health and Social Care Bill 2012 was amended by the House of Lords to ensure that the secretary of state continues the promotion in England of a comprehensive health service designed to secure improvement in the physical and mental health of the people of England. This was intended to be a statement of parity between mental and physical health and the state's responsibility for the promotion of such parity is now part of an Act of Parliament. Why does the Supreme Court in Rabone apply the operational duty of the state unequally for physical and mental health? Is it not a problem that it did?

\section{Problem 4: the assessment of risk}

The previous issues we have considered relate to the degree of control the state is able to exercise over different categories of patient. The operational duty also requires the presence of a 'real and immediate' risk.

When one examines the history of a patient such as Melanie Rabone, a very persuasive, indeed moving, narrative can emerge linking previous events (such as a sequence of suicide attempts, significant symptoms of depression, warnings from others, and so on) to an eventual suicide. The history is one that is consistent with the outcome. Why, then, is there a difficulty in predicting, with a significant degree of accuracy, such an outcome?

The problem is that there are numerous in-patients admitted to psychiatric units who have a history that would be consistent, with hindsight, with an outcome such as suicide. Yet, such an outcome is rare. Let us consider some data on in-patient deaths by suicide (which include those occurring during periods of trial leave). In 2009 there were, in England, 84 such deaths. ${ }^{11}$ These occurred in the course of approximately 120000 admissions involving 108000 people. The rate of suicide therefore was around 1 in 1400 admissions. We cannot be certain what proportion of the admissions were for people considered to be at risk of suicide, but a study that examined reasons for admission for a number of mental health trusts in London found that for $36 \%$, prevention of suicide was the 'major' (21\%) or a 'contributory' (15\%) factor. ${ }^{12}$ Even if we take only those where it was the major factor (and disregard the fact that some in-patient suicides would not even be identified as belonging to any prevention of suicide group), the rate of in-patient suicide would be around 1 in 285 patients. Presumably for all of these patients, sufficiently apparently suicidal to be admitted to a psychiatric unit, an entirely plausible narrative culminating in a suicide could, with hindsight, have been constructed. But how is one to predict who that one patient who will die by suicide will be?

Rare events are virtually impossible to predict with any degree of accuracy. 'False positives' will overwhelm the number of 'true positives'. A meta-analysis of suicide prediction for the year following discharge from hospital concluded that if the rate of suicide in the year postdischarge were, say, 1 in 250, only 1 in 100 of patients judged to be at 'high risk' using a risk assessment instrument would complete suicide. $^{13}$

In-patient suicide attempts are more common. In the South London and Maudsley NHS Foundation Trust in the 3 years from 2007, these averaged 34 per annum. ${ }^{14}$ There were just under 5000 admissions per annum, so the rate of suicide attempts was around 1 in 140 admissions. Even these are virtually impossible to predict without a vast preponderance of false positives. (During those 3 years there was only 1 death by suicide.)

These figures cast serious doubt on the risk assessments made in the Rabone case retrospectively by the two experts. How can one arrive, from an actual risk of in-patient suicide of 1 in 285 admissions (0.4\%) in patients admitted to hospital where clinicians cite prevention of suicide to be a major reason, to an estimate of $20 \%$, much less $70 \%$ ? Bear in mind also that the risk estimate did not cover the entire admission period, but related to 3 specified days.

If the court had been advised that the risk was 1 in 285 , or even 1 in 100, would that have been regarded as constituting a 'real and immediate' risk as required for an operational duty under Article 2?

It can be argued that if a clinician has stated that the reason for admission is to prevent suicide, and then the patient subsequently does die by suicide, particularly as an in-patient, there is a presumption that the treatment has been inadequate. This, of course, represents a quite extreme form of 'hindsight bias' - knowledge that an event happened makes it much more likely, with hindsight, that apparently foreseeable causes will be ascribed than if the outcome is unknown. ${ }^{15}$ Although this represents poor logic, perhaps clinicians also need to think about whether it is sensible to talk about admitting someone because of the 'risk of suicide', when that risk is, in the short term, somewhere around 1 in 250, or even if it were 1 in 100. Patients are generally admitted because they are ill and need treatment to alleviate unnecessary suffering or the damaging effects of their illness on their lives in a broad range of possible domains.

\section{Conclusions}

To avoid misunderstanding, we are not claiming that Melanie Rabone did or did not have decision-making capacity, nor that she should or should not have been detained under the Mental Health Act. Our interest is in where the line for an operational duty under Article 2 (the 
right to life) should be placed in healthcare settings and in some significant general questions raised by the Supreme Court judgment.

By omitting consideration of the group of general medical or surgical patients who are unable to give informed consent to treatment on account of a lack of decisionmaking capacity, the court oversimplified the nature of the differences between the informal psychiatric patient and the general patient. Determining where the line for an operational duty under Article 2 should be placed becomes substantially more difficult were this group to be included. It is possible that with this evolving law the operational duty might extend in the future to medical and surgical patients in whom decision-making capacity is absent, including patients seen in accident and emergency departments or resident care homes. Whether this would enhance the protection of life as opposed to enhancing clinical governance, monitoring, state-mandated regulatory measures, and so on, or how this might work in practice are questions beyond the scope of this article. The criticism that the Rabone decision discriminates against persons with a mental illness would obviously no longer apply.

Related to the problem of where the line (or threshold) lies for an operational duty is the role of capacity in making treatment decisions, and we note that the irrelevance of this patient characteristic in the Mental Health Act represents a differentiation that some regard as discriminatory and may now be contributing to the shadow that overhangs those with a mental illness.

The difference between the detained psychiatric patient and the informal psychiatric patient was considered by the Supreme Court as 'one of form, not of substance'. Such a state of affairs is certainly not one the Percy Royal Commission of 1957 intended when it recommended the principle, accepted by parliament, that informal psychiatric patients should be in the same position as any other patients. ${ }^{16}$ This became the basis for the 1959 Mental Health Act, and this principle - parity of physical and mental health - has, in theory at least, remained in place. The Supreme Court judgment in Rabone, by effectively accepting a disparity between mental and physical health, makes the line where the operational duty under Article 2 now falls a mental $v$. physical health line.

Our consideration of the expert risk assessments offered to the court indicates that, when set against available data on in-patient suicide, they represented a gross overestimate of the likelihood of suicide. A question thus arises as to whether the order of the magnitude of the risk of suicide that obtains in real practice can ever accord with the requirement of the Article 2 operational duty that it be 'real and immediate'. It is not possible to envisage every situation that might arise in practice, but given the statistics, short of a patient stating plainly and with conviction that suicide is their immediate intention, it would seem most unlikely. In relation to the line where an operational duty should be drawn, it could be argued that a 'real and immediate' risk to life is likely to be substantially more predictable in serious medical or surgical cases where treatment failures may, with a high likelihood, result in death. We add as a general observation that the misunderstanding of the true likelihood of in-patient suicide in the Supreme Court's deliberation is a concrete instance of the problem of making 'risk' such a central plank in mental health law.

The Supreme Court judgment in Rabone on the operational duty to protect the right to life brings to the surface some of the most important problems in mental health law. The judgment shows how much work there is left to do to resolve them.

\section{About the authors}

George Szmukler is Professor of Psychiatry and Society, Institute of Psychiatry, King's College London, Genevra Richardson is Professor of Law, King's College London, and Gareth Owen is Clinical Senior Lecturer, Institute of Psychiatry, King's College London, and Honorary Consultant Psychiatrist, South London and Maudsley NHS Foundation Trust.

\section{References}

1 Osman v United Kingdom (2000) 29 EHRR 245.

2 Keenan v UK (2001) 33 EHRR 38.

3 Edwards v United Kingdom (2002) 36 EHRR 487.

4 Savage $v$ South Essex Partnership NHS Foundation Trust [2008] UKHL 74; [2009] 1 AC 681.

5 Rabone and another v Pennine Care NHS Foundation Trust [2012] UKSC 2.

6 Rabone and Pennine Care NHS Trust [2009] EWHC 1827 (QB).

7 Rabone and Pennine Care NHS Trust [2010] EWCA Civ 698.

8 Raymont V, Bingley W, Buchanan A, David AS, Hayward P, Wessely S, et al. Prevalence of mental incapacity in medical inpatients and associated risk factors: cross-sectional study. Lancet 2004; 364: 1421-7.

9 Owen GS, Szmukler S, Richardson G, David AS, Hayward P, Rucker J, et al. Mental capacity and psychiatric in-patients: implications for the new mental health law in England and Wales. Br J Psychiatry 2009; 195: 257-63.

10 Dawson J, Szmukler G. Fusion of mental health and incapacity legislation. Br J Psychiatry 2006; 188: 504-9.

11 Appleby L, Kapur N, Shaw J, Hunt IM, Flynn S, While D, et al. National Confidential Inquiry into Suicide and Homicide by People with Mental IIIness Annual Report: England, Wales, Scotland, and Northern Ireland. University of Manchester, 2012.

12 Flannigan CB, Glover GR, Wing JK, Lewis SW, Bebbington PE, Feeney ST. Inner London collaborative audit of admission in two health districts. III: Reasons for acute admission to psychiatric wards. Br J Psychiatry 1994; 165: 750-9.

13 Large M, Sharma S, Cannon E, Ryan C, Nielssen O. Risk factors for suicide within a year of discharge from psychiatric hospital: a systematic meta-analysis. Aust N Z J Psychiatry 2011; 45: 619-28.

14 South London and Maudsley NHS foundation Trust. Annual Report and Summary Accounts 2009/2010. SLAM, 2010.

15 Guilbault RL, Bryant FB, Howard Brockway J, Posavac EJ. A metaanalysis of research on hindsight bias. Basic Applied Soc Psychol 2004; 26: 103-17.

16 HM Government. Report of the Royal Commission on the Law Relating to Mental Illness and Mental Deficiency 1954-1957 (Cmnd 169). HMSO, 1957. 